\title{
Industry 4.0:Social Challenges and Risks
}

\author{
Gilberto Marzano \\ Rezekne Academy of Technologies \\ Rezekne, Latvia \\ Społeczna Akademia Nauk w Łodzi \\ Lodz, Poland \\ gilberto.marzano@rta.lv
}

\author{
Luis Ochoa Siguencia \\ Sport and Tourism management \\ Akademia Wychowania Fizycznego w Katowicach \\ Katowice,Poland \\ l.ochoa@awf.katowice.pl
}

\begin{abstract}
Industry 4.0 is a term first introduced by the German government during the Hannover Messe fair in 2011 when it launched an initiative to support German industry in tackling future challenges. It refers to the 4 th industrial revolution in which disruptive digital technologies, such as the Internet of Things (IoT), Internet of Everything (IoE), robotics, virtual reality (VR), and artificial intelligence (AI), are impacting industrial production.

The new industrial paradigms of Industry 4.0 demand a socio-technical evolution of the human role in production systems, in which all working activities of the value chain will be performed with smart approaches.

However, the automation of processes can have unpredictable effects.

Nowadays, in a smart factory, the role of human operators is often only to control and supervise the automated processes. This new condition of workers brought forth a paradox: malfunctions or irregularities in the automated production process are rare but challenging.

This article discusses the challenges and risks that the 4th industrial revolution is bringing to society.

It introduces the concept of the Irony of Automation. This propounds that the more reliable an automated system, the less human operators have to do and, consequently, the less attention they pay to the system while it is operating.

The authors go on to discuss the human-centered approach to automation, whose purpose is not necessarily to automate previously manual functions but, rather, to enhance user effectiveness and reduce errors.
\end{abstract}

Keywords - human-centered approach Industry 4.0, Internet of Everything, irony of automation.

\section{INTRODUCTION}

Industry 4.0 is a term first introduced in 2011 by the German federal government when, at the Hanover Messe fair, it presented a project hypothesis aimed at supporting German industry to address the challenges of the future brought by the expansion and progress of digital technologies [1].
The term Industry 4.0 clearly calls to mind the fourth Industrial Revolution where the Internet of Things (IoT), the Internet of Everything (IoE), the Web of Things (WoT), robotics, virtual reality (VR), artificial intelligence (AI), and ultra-fast connections play a primary role [2].

The main innovation of Industry 4.0 is the redesign of technological and organizational processes as a result of the integration of different sources of information with management and production processes. This is the result of the unconventional use and combination of already existing technologies to create new business solutions.

Industry 4.0 leverages the opportunities offered by the digitation of data and by information technology. It encompasses some main specific fields:

- Autonomous driving. This encompasses three classes of vehicles: semi-autonomous, sufficientautonomous, and fully-autonomous.

- 3D printing. This consists of creating physical objects by printing them from a digital model.

- Advanced robotics. This is a wide-ranging field that includes biomimicry, namely applications and systems that are modeled on biological entities and processes.

- New materials. These are materials that are recyclable and adaptive, such as metals with memory, ceramics and crystals that turn pressure into energy, and materials that possess capabilities that enable self-healing and self-cleaning.

- IoT and IoE applications. These aim to connect things (devices, products, services, places, etc.) and people through smart sensors and various platforms (Fig. 1).

- Biological applications. Genome sequencing and synthetic biology will not only have profound consequences in medicine but also in agriculture and biofuel production.

Online ISSN 2256-070X

https://doi.org/10.17770/etr2021vol2.6546

(C) 2021 Gilberto Marzano, Luis Ochoa Siguencia.

Published by Rezekne Academy of Technologies.

This is an open access article under the Creative Commons Attribution 4.0 International License. 


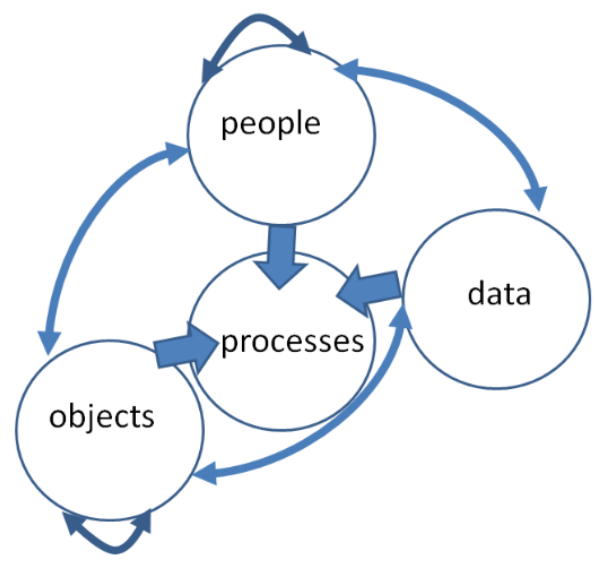

Fig. 1. The IoE paradigms (author's own source)

The digital revolution and the new industrial paradigms of Industry 4.0 demand a socio-technical evolution of the human role in production systems, in which all working activities of the value chain will be performed with smart approaches.

This article discusses some of the challenges and risks related to the fourth industrial revolution and Industry 4.0.

It introduces the concept of the Irony of Automation, and argues for a human-centered approach to enhance user effectiveness and reduce technical errors.

\section{OBJECTIVE OF RESEARCH AND METHODOLOGY}

The objective of this research is to investigate the social challenges and technical risks associated with the development of Industry 4.0. In particular, this research aims to identify strategies and solutions that may be adopted in order to overcome the technological pitfalls that, due to human factors, may affect the implementation of intelligent systems.

For this research, a procedure was adopted for the literature review aimed at attaining the research goal [3], [4]. The procedure followed the following phases:

- Define the research question: Industry 4.0 sociotechnical issues and solution approaches.

- Define the search plan: identification of databases (Web of science, Scopus, IEEE, ACM, SAGE, Google Scholar) and period of investigation (2010-2021).

- Search for relevant literature: use of appropriate keywords.

- Apply exclusion criteria: including only evidence-based materials.

- Analyze materials: reading and evaluation of selected items.

The transformations in the labor market have been analyzed, considering the human factors underlying competition with machines and control of the automated process.

The technical risks have also been considered, focusing on the security and ethics of intelligent systems. This paper also takes advantage of the results of previous studies on decision making and augmented cognition, as well as the experience gained in teaching Industry 4.0.

From the literature analysis, it emerged that:

- an evidence-based understanding of the implications of an algorithm's application is necessary before its large-scale use.

- human-centered automation may reduce errors and risks in intelligent manufacturing systems.

Moreover, over the last few years, many publications have dealt with the concept of "the irony of automation" that was first expounded by the cognitive psychologist Bainbridge (1983) [5], and have reconsidered Rasmussen's work (1983) [6] on operator performance in process systems in the light of intelligent system technology.

According to Google Scholar, the number of citations of Bainbridge's work have risen from around 1,800 in early November 2016 [7] to over 2,200 in March 2021, whilst citations of Rasmussen's article exceeded 4,700.

\section{SOCIAL CHALLENGES OF INDUSTRY 4.0}

The impact that Industry 4.0 will have on society divides experts [8], [9]. The techno-pessimists argue that technological advances will have a critical impact on the labor market, at least in the short term. They underline that, over the last few years, automation processes have begun substituting the jobs of many manual workers, as well as those of bookkeepers, cashiers, and telephone operators. The techno-optimists, on the contrary, claim that technology will soon bring economic growth.

Some economists talk about secular stagnation, a term coined by Alvin Hansen in 1938 [10], forecasting a situation of persistent shortfalls in demand and wage squeezing [11]. They believe that new technology can lead to a temporary fall in productivity due to the reorganization of workers' competence.

Brynjolfsson and McAfee (2014) [12] emphasized that, to take advantage of the fourth industrial revolution's opportunity, it is necessary to understand the critical impact that this revolution will have on society. Accordingly, an effort is required to recognize and deal with new social challenges facing people and organizations, and an investment must be made in analyzing the seriousness of the risks that are intrinsic in the extended use of intelligent systems in the social sphere and in industrial production processes [13].

From this perspective, the loss of traditional jobs and the reorganization of workers' competence, although crucial aspects in themselves, are only one part of the issue.

A hugely critical issue concerns internet-based participation. This can hide the risks of new forms of tyranny developing based on the consensus obtained through social media. E-democracy, e-participation, and virtual decision-making [14 open a question about responsibility. What is the responsibility of decisionmakers in crowd-based participatory processes? They could shift blame by transferring responsibility for a problematic decision to the crowd. Taking inspiration from the famous book "Escape from freedom” by Fromm (1941) 
[15], the problem could be reformulated as one of "escape from responsibility."

Another problem arises with the drive towards full automation. It might not be wise to automate tasks just because it is possible to do so. Indeed, there are problems with machine control and interaction that are connected with full automation. Moreover, interactions of humans with machines and intelligent programs bring new, possibly unforeseen, social risks that research should urgently address.

\section{IRONY OF AUTOMATION}

The irony of automation argues that, in an automated system, there are always some circumstances that are not expected. An automated system is designed to handle only things that have been predicted. Design constraints limit even intelligent systems based on a machine learning approach.

Discussing how automation of industrial processes may expand rather than eliminate problems with the human operator, Bainbridge introduced the concept of the irony of automation:

The important ironies of the classic approach to automation lie in the expectations of the system designers, and in the nature of the tasks left for the human operators to carry out. The designer's view of the human operator may be that the operator is unreliable and inefficient, so should be eliminated from the system [5].

The above attitude of the automation designers is still diffused. They do not understand that automated systems should be designed to support human beings. Accordingly, they should reduce the human workload but not eliminate the human intervention.

However, if a designer is asked to design only some complex system's elementary functions, the designer task is completed when these functions work. Nevertheless, in a complex system, pieces of hardware and software are interconnected and depend on other hardware and software pieces. Consequently, integrated control and feedback are needed since unexpected events can occur in any complex system [16].

Moreover, according to [17], many types of automation failures, including software bugs and hardware failures, lie in how automation performs as the designer intended but not as the user intended.

Analyzing and discussing the still unresolved ironies of automation, Strauch observes that to solve them, one must recognize them [7]. In this regard, the author claims that the way to do it is necessary that system designers, trainers, managers, and regulators work together to address the potential adverse effects of automation.

\section{TECHNICAL RISKS OF INDUSTRY 4.0}

The disruptive spread of the IoT and IoE applications leads to new kinds of security problems and errors that could result from algorithms that do not control and manage unpredicted odd or rare circumstances. At the current time, securing the systems in the manufacturing environment is an issue that is rapidly gaining attention in Industry 4.0.

Moreover, an inherent technical risk in complex process automation is the unpredictability of the human control over algorithms and the serious consequences this can have. Indeed, although machine performance is superior, in certain respects, to human abilities, software applications might not always be intrinsically reliable.

There are many problems that arise in relation to intelligent systems. One is the reliability of the humans who work on the control of automated processes.

Investigating and studying methods for addressing and overcoming cognitive bottlenecks is the aim of the research field of Augmented Cognition. It focuses on accelerating the production of novel concepts in human-system integration, addressing issues such as limitations in attention, memory, learning, comprehension, visualization abilities, and decision making, and leveraging technologies that assess the humans' cognitive status in real-time.

A second problem concerns automated responses to critical situations. Intelligent applications process the data that programs implemented by human experts are expected to use. Algorithms, even created by human experts, analyze the data and activate the optimal response, choosing it from among the range of possible responses previously identified by the same or other experts. At this time, intelligent applications cannot produce responses that go beyond the knowledge domain defined by human experts. Indeed, current research on machine learning is aimed at enabling computer programs to acquire knowledge and skills, and even improve their own performance. Big Data provides the raw material that allow machines to perform assigned tasks more efficiently. Nevertheless, situations can occur where a machine is not able to find the appropriate response. In such cases, human operators should intervene, but the more reliable the intelligent system, the less human operators have to do, and so the less attention they pay to the system while it is operating. In other words:

- Reliable systems tend to make it difficult for operators to notice when something is wrong; if an error is not noticed, it can eventually become the "new normal."

- The best way to avoid automation errors is rigorous Sampling and Testing. But this is expensive.

In this regard, it has been suggested to focus on keeping operators engaged, since they will be better prepared to notice when something is wrong.

However, the main issues with intelligent system lie in their expertise.

\section{HUMAN EXPERTISE}

Intelligence is far easier to recognize than to define, and there is a profound difference between human and machine intelligent behavior. 
Researchers in the AI scope are concentrated on programming machines to perform what is considered an intelligent behavior [18].

Accordingly, they focus on knowledge and expertise accumulation and application. In a machine, intelligent behavior depends on the knowledge of the context [19].

The basic assumptions about knowledge in the AI field are [20]:

- Knowledge is modular, it can be broken down into sub-parts and subsystems.

- All the important knowledge can be made explicit, verbalized, and then adequately represented as data structures and procedures.

- All the necessary knowledge exists in an expert's head.

- The problem space is closed, i.e., all the relevant knowledge for a set of tasks in a domain can be isolated and contained within a computer knowledge base.

From these assumptions, the dependence of an intelligent machine on the human approach to automation is clearly evident.

The unabated progress of Industry 4.0 increases the urgent necessity to pursue and conduct further research into an integrated and innovative approach to human-centered automation.

\section{THE HUMAN CENTERED APPROACH TO AUTOMATION}

Human-centered automation is automation whose purpose is not necessarily to automate all manual functions, but rather to enhance user effectiveness and reduce errors.

In 1992, Sharidan identified 10 degrees of automation that should be considered in supervisory control. These degrees, that remain a landmark in current research on autonomous controlling, are shown in Table 1.

TABLE 1 SCALE OF DEGREES OF AUTOMATION (SOURCE: SHERIDAN, 1992, P. 358)

\begin{tabular}{|c|l|}
\hline 1. & $\begin{array}{l}\text { The computer offers no assistance, human must } \\
\text { do it all. }\end{array}$ \\
\hline 2. & $\begin{array}{l}\text { The computer offers a complete set of action } \\
\text { alternatives, and }\end{array}$ \\
\hline 3. & narrows the selection down to a few, or \\
\hline 4. & suggests one, and \\
\hline 5. & $\begin{array}{l}\text { executes that suggestion if the human approves, } \\
\text { or }\end{array}$ \\
\hline 6. & $\begin{array}{l}\text { allows the human a restricted time to veto before } \\
\text { automatic execution, or }\end{array}$ \\
\hline 7. & $\begin{array}{l}\text { executes automatically, then necessarily informs } \\
\text { the human, or }\end{array}$ \\
\hline 8. & informs him after execution only if the asks, or \\
\hline 9. & $\begin{array}{l}\text { informs him after execution if it, the computer, } \\
\text { decides to. }\end{array}$ \\
\hline 10. & $\begin{array}{l}\text { The computer decides everything and acts } \\
\text { autonomously, ignoring the human. }\end{array}$ \\
\hline
\end{tabular}

It has been underlined that one test of whether a proposed piece of automation is human-centered is to pose the question: "Does it enhance user effectiveness?" [21]. Of course, if the answer is yes, the onus is on the designer to demonstrate how.

The analysis of issues particularly relevant in urban operations and chemical/biological incident responses suggests that the effects of technological change should be previously understood before introducing robot systems into an existing workplace [22].

In this regard, (Robin) Murphy's Law is often quoted, which states that: "any deployment of robotic systems will fall short of the target level of autonomy, creating or exacerbating a shortfall in mechanisms for coordination with human problem holders” [23].

Accordingly, the human-centered automation design should consider that intelligent human and machine agents must be combined appropriately.

One should not forget that machine agents are knowledge-based software objects with both strengths and weaknesses. They are expected to act in timely and consistent ways but have very fragile and domain-limited knowledge. They may be unable to behave reliably when an unpredicted or anomalous event occurs.

Human agents should be responsible for identifying and compensating for the limitations of the machine agents. In designing an automated system, a way should always be provided to allow the user to intervene and take control of the system. It is also essential that automation design supports the operator's awareness of both the current system state as well as the states of the machine agents so as to ensure that the two sets of agents are operating in complementary mode [21] .

Coordinating and integrating the interaction between humans and machines is not a speculative philosophical question. It encompasses technical problems that lie in the realm of human-robot coordination [24], [25], humancentered artificial intelligence [26], [27], and Digital Social Innovation [28].

A paradox has been recognized in designing humancentered automotive automation systems. It goes beyond the specific field of application:

"Trust in and understanding automation can be a vicious cycle. On the one hand, humans may not be able to fully understand an automation system until they can develop a certain level of trust in the system to reach their goal. On the other hand, the more humans understand the automation system, the more they can develop an appropriate trust system.” [29].

Finally, according to Shneiderman, “an important research direction is to develop objective measures of the levels of control and autonomy, tied to diverse tasks. Such measures would stimulate more meaningful design discussions, which would lead to improved guidelines, evaluations, and theories" [23]. 


\section{CONCLUSION}

There is widespread concern amongst operators of complex systems that intelligent automation and Industry 4.0 may reduce the operator's ability to assume control of sophisticated systems in anomalous situations. Moreover, hyperconnected and intelligent systems are vulnerable to security risks [30].

Klaus Schwab, the German engineer and economist who is the founder and executive chairman of the World Economic Forum, claimed that:

"The fourth industrial revolution may be driving disruption, but the challenges it presents are of our own making. It is thus in our power to address them and enact the changes and polices needed to adapt (and flourish) in our emerging new environment.” [31].

The authors' opinion is that in order to face the challenges of the fourth industrial revolution, it is necessary to capitalize the knowledge needed to understand and direct the ongoing transformations. To cope with these transformations, both technical knowledge and innovative skills are required. Integrated technical skills, digital literacy, critical thinking, and creativity are all essential to counter the narrative that sees technology serving a global conspiracy by cynical and unscrupulous multinationals.

Accordingly, teaching Industry 4.0 should reinforce the integration of student competence so as to face the challenges brought by the digital revolution. The experience obtained in introducing Industry 4.0 to the mechatronics study program of the Faculty of Engineering at the Rezekne Academy of Technologies has demonstrated the importance of creating a complete learning program that encompasses all the aspects that are connected to Industry 4.0 [32].

\section{ACKNOWLEDGEMENTS}

This paper was supported by the European project NewMetro (embeddiNg kEts and Work based learning into MEchaTROnic profile) - Project n. 600984-EPP-12018-1-IT-EPPKA2-SSA.

This document reflects the views only of the authors, and the Commission cannot be held responsible for any use which may be made of the information contained there in.
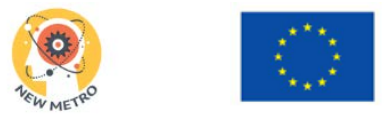

Co-funded by the Erasmus+ Programme of the European Union

\section{REFERENCES}

[1] J. Qin, Y. Liu and R. Grosvenor, “A categorical framework of manufacturing for industry 4.0 and beyond”, Procedia cirp, 52, 173-178, 2016.

[2] H. Lasi, P. Fettke, H.G. Kemper, T. Feld, and M. Hoffmann, "Industry 4.0", Business \& information systems engineering, 6(4), 239-242, 2014.

[3] A. Booth, A. Sutton and D. Papaioannou, D., Systematic approaches to a successful literature review, SAGE Publication, 2016.
[4] J. Jesson, L. Matheson and F.M. Lacey, Doing your literature review: Traditional and systematic techniques. SAGE publication, 2011.

[5] L. Bainbridge, “Ironies of automation”, Automatica, 19(6), pp. 775-779, 1983.

[6] J. Rasmussen, “Skills, rules, and knowledge; signals, signs, and symbols, and other distinctions in human performance models”, IEEE transactions on systems, man, and cybernetics, (3), pp. 257-266, 1983.

[7] B. Strauch, "Ironies of automation: Still unresolved after all these years”, IEEE Transactions on Human-Machine Systems, 48(5), pp. 419-433, 2017.

[8] T. Devezas and A. Sarygulov, Industry 4.0. Basel: Springer, 2017.

[9] A. Sartal, R. Bellas, A. M. Mejías and A. García-Collado, “The sustainable manufacturing concept, evolution and opportunities within Industry 4.0: A literature review", Advances in Mechanical Engineering, 12(5), 2020.

[10] A, Hansen, Full Recovery or Stagnation, New York: W.W. Norton \& Co, 1938.

[11] P. Krugman, "Four observations on secular stagnation”, Secular stagnation: Facts, causes and cures, pp. 61-68, 2014.

[12] E. Brynjolfsson and A. McAfee, The second machine age: Work, progress, and prosperity in a time of brilliant technologies, WW Norton \& Company, 2014.

[13] G. Marzano, M. Grewinsky, M. Kawa and J. Lizut, Towards changes of the labor market skills and competence, Elipsa, 2020.

[14] L. Hennen, I. Van Keulen, I. Korthagen, G. Aichholzer, R. Lindner and R.Ø. Nielsen, European e-democracy in practice, 2020.

[15] E. Fromm, Escape from freedom, Rinehart inc., 1941.

[16] J. Ladyman, J. Lambert and K. Wiesner, “ What is a complex system?”, European Journal for Philosophy of Science, 3(1), 33-67, 2013.

[17] A. Sebok and C. D. Wickens, "Implementing lumberjacks and black swans into model-based tools to support humanautomation interaction”, Human factors, 59(2), 189-203, 2017.

[18] R. Fikes and T. Garvey, "Knowledge Representation and Reasoning - A History of DARPA Leadership”, AI Magazine, 41(2), pp. 9-21, 2020.

[19] J. Qin, "Knowledge organization and representation under the AI lens”, Journal of Data and Information Science, 6(1), pp. 317, 2020.

[20] G. Alor-Hernández and R. Valencia-García, (Eds.). Current trends on knowledge-based systems (Vol. 1). Springer International Publishing, 2017.

[21] C. M. Mitchell, C.M. "Human-Centered Automation: A Philosophy, Some Design Tenets, and Related Research", In Human Interaction with Complex Systems (pp. 377-381). Springer, 1996.

[22] D. D. Woods, J. Tittle, M. Feil and A. Roesler, "Envisioning human-robot coordination in future operations", IEEE Transactions on Systems, Man, and Cybernetics, Part C (Applications and Reviews), 34(2), pp. 210-218, 2004.

[23] B. Shneiderman, "Human-centered artificial intelligence: Reliable, safe \& trustworthy”, International Journal of Human-Computer Interaction, 36(6), pp. 495-504, 2004.

[24] S. Musić and S. Hirche, "Control sharing in human-robot team interaction”, Annual Reviews in Control,44, pp. 342-354, 2017.

[25] S. Nyholm and J. Smids, “Automated cars meet human drivers: responsible human-robot coordination and the ethics of mixed traffic”, Ethics and Information Technology, pp. 1-10, 2018.

[26] M. O. Riedl, "Human-centered artificial intelligence and machine learning”, Human Behavior and Emerging Technologies, 1(1), pp. 33-36, 2019. 
[27] A. Schmidt, "Interactive Human Centered Artificial Intelligence: A Definition and Research Challenges", In Proceedings of the International Conference on Advanced Visual Interfaces (pp. 1-4), Sptember 2020.

[28] S. Karajz, "The impact of Industry 4.0 on the processes of social innovation”, Theory Methodology Practice: Club of Economics in Miskolc, 17(SI), pp. 3-10, 2021.

[29] H. Muslim and M. Itoh, "A theoretical framework for designing human-centered automotive automation systems”, Cognition, Technology \& Work, 21(4), pp. 685-697, 2019.
[30] M. Dawson, “Cyber security in industry 4.0: The pitfalls of having hyperconnected systems", Journal of Strategic Management Studies, 10(1), pp. 19-28, 2018.

[31] K. Schwab, The fourth industrial revolution. Currency, 2017.

[32] G. Marzano and A. Martinovs, "Teaching Industry 4.0", In SOCIETY. INTEGRATION. EDUCATION. Proceedings of the International Scientific Conference (Vol. 2, pp. 69-76), May 20 